\title{
Fat supplementation in animal production-monogastric animals
}

\section{By C. P. Freeman, Unilever Research Laboratories, Colworth House, Sharnbrook, Bedfordshire}

Fats are used extensively to supplement the diets of pigs, poultry and fish largely because of the movement towards higher energy-containing diets in intensive animal production systems, and the favourable costs of fats relative to other sources of energy. Thus the last decade has seen a threefold increase in the use of fats during a period of almost static feed production (Table I), of which slightly more than $50 \%$ has been utilized in pig and poultry rations. As energy sources per $s e$, the non-additive relationship between fats and the higher efficiency of utilization of their metabolizable energy (ME), relative to that of carbohydrate or protein, require particular consideration with respect to their energy value to the animal. The fatty acid composition of fat not only affects its energy value but has a significant effect on the economic value of the end-product, both in its chemical composition and in the more subjective measurements of meat quality. The range of fats available is wide, and they must be selected carefully with regard to energy yield, and their effect on the overall cost of production and product value. Some of these considerations will be discussed, together with some specific applications of fats in the nutrition of particular classes of stock.

\section{The energy value of fats}

The exploitation of fats as contributors of dietary energy to the monogastric animal requires precise and meaningful energy values for diet formulation and assessment of their economic value. The principal determinant of the energy value of fat to the animal is its true digestibility. Most published results refer to apparent digestibility; corrections are made occasionally for the contribution of endogenous fat to total faecal fat but reliable estimates of endogenous fat output in defined dietary situations are sparse. Thus, although the results of Lewis \& Payne (1966) indicate that an addition of $9 \%$ to the apparent digestibility may provide true digestibility values by the chick, for a range of fats, isotope studies in the pig

Table I. Use of fats and oils in compound feed in the UK'

$\begin{array}{lccccc}\text { Year... } & 1973 & 1975 & 1977 & 1979 & 1981 \\ \begin{array}{l}\text { Fats and oils } \\ \quad\left(\text { ton } \times 10^{3}\right)\end{array} & 59.1 & 83.2 & 94.2 & 123.7 & 187.6 \\ \begin{array}{l}\text { Total compound feed production } \\ \left(\text { ton } \times 10^{6}\right)\end{array} & 11 \cdot 2 & 10.2 & 10.8 & 11.6 & 11 \cdot 0\end{array}$

-Source: UK Agricultural Supply Trade Association, personal communication. 
(Freeman et al. 1968 ) suggest that the assumptions on which such corrections are based may be invalid, and raise questions about the origin and definition of endogenous fat output.

In practical terms the factors which influence the digestibility of fats by monogastric animals include the extent of saturation of the constituent fatty acids, the proportion of glycerides, the chain length of the fatty acids, the level of inclusion and the age of the animal. The degree of unsaturation is positively, but not linearly, related to digestibility. Conversely, increasing chain length of individual fatty acids has a depressant effect on digestibility in both pigs and poultry. The proportion of glycerides in dietary fat (ratio of free fatty acid:glyceride) is important in regulating the supply of monoglycerides in the lumen of the intestine, and an increase in the free fatty acid content of the dietary fat has been shown to depress fat digestibility in the young and adult bird and in the pig (Shannon, 1971; Freeman, 1976). Synergism between fats is a distinguishing feature in the utilization of fats by monogastrics compared with ruminant species. Although this effect has mainly been ascribed to an effect of unsaturated fats or fatty acids on the digestibility of saturated fats, there is little doubt that all three factors previously mentioned are intimately involved in a highly interactive process. The explanation of these inter-relationships lies in an understanding of the mechanisms governing intestinal digestion and absorption and, in particular, the role of amphiphiles in the micellar solubilization of non-polar solutes (Freeman, 1976). There is some evidence that the digestibility of saturated fats is depressed at high inclusion levels in the diet (Freeman, 1976) and a similar interaction between level of inclusion and free fatty acid content is observed in the laying hen (Shannon, 1971).

Amongst the extrinsic factors which may influence fat digestibility, the age of the animal is the most significant. In general, the capacity to utilize fat increases gradually with age; there is, however, a period of growth, for example in the very young chick, where a physiological inadequacy in bile secretion imposes severe limitations on both the digestive and absorptive processes.

Similarly, in the milk-fed pig, the capacity to assimilate fat from the sows' milk or from a liquid substitute is significantly greater than when fat is presented in meal form. Hence the type and form of presentation of supplemental fat must reflect the physiological status of the animal. Other factors which may impair the digestibility of fat and hence its digestible energy value include the microbial environment of the gut, the feeding regimen and its effect on lumenal flow rates, the presence of divalent cations such as calcium or magnesium in the diet, and the fibre content of the diet (see Freeman, 1976).

Efficiency of utilization. When long-chain fatty acids and carbohydrates are metabolized to satisfy body energy demands, their efficiency of utilization is similar (Blaxter, 1962), in contrast to their relative efficiencies of utilization in the accretion of body tissue. The energy cost of the digestion, absorption, transport and deposition in adipose tissue of dietary fats appears to be small compared with the synthesis of fat from carbohydrate or protein. The results of Hillcoat \& 
Annison (1974) are consistent with efficiencies of utilization of carbohydrate (starch) and fats of 75 and $90 \%$ respectively in the pig fed above maintenance. Similar values have been obtained in the chick (De Groote, 1969). Simple energetic considerations would suggest that the efficiency of transfer of individual fatty acids to adipose tissue will differ depending on the extent of structural modification invoked; therefore, coefficients of utilization will vary in relation to the fatty acid composition of the dietary fat. Although De Groote et al. (1971) failed to demonstrate any significant difference in the efficiencies of utilization of a wide range of supplemental fats, this was probably due to the high variability inherent in the techniques used. The absence of an increase in the efficiency of utilization of ME with diets containing hydrogenated coconut oil (Carew et al. 1964) is explained by the high content of medium-chain fatty acids in coconut oil which are not deposited directly in adipose tissue.

It has been suggested that the low heat increment due to fats can be exploited to alleviate heat stress at high environmental temperatures, but results in support of this hypothesis in the chick are inconclusive (Kubena et al. 1973; Dale \& Fuller, 1980). More recently, Mateos \& Sell (198I) have proposed that a part of the 'extracaloric' effect of fat in the laying hen is due to a retardation in the rates of passage of other nutrients along the digestive tract, particularly carbohydrates, but care has to be taken in the definition of the 'extra-caloric' effect attributable to fat, and a distinction made between the associative effects of fats on other dietary components.

\section{Fat supplementation and the growing animal}

Increasing the energy concentration of the diet results in changes in food consumption and productive efficiency by the animal. Fisher $\&$ Wilson (1974) have defined the relationships between food intake, ME intake, weight gain, food conversion efficiency (FCE) and dietary energy concentration in the broiler as linear regressions using $\mathrm{I} 60$ published estimates of response. Although the response was variable, food consumption tended to be depressed as dietary energy level was raised; at the same time live-weight gain and dietary energy intake were increased. The net, and most consistent effect, was an improvement in FCE as dietary energy concentration was increased. Although studied less comprehensively, similar effects have been observed in the growing pig (Cooke et al. 1972).

The advantages of high-energy diets for the growing animal are apparent, and a wide range of fats has been used to supplement the diets of the growing pig, turkey and broiler chick. The inclusion of tallow, lard, soya-bean oil, and rapeseed oil in the diets of growing pigs has led to consistent improvements in the efficiency of feed utilization (Greeley et al. 1964; Leibbrandt et al. 1975; McDonald \& Hamilton, 1976). A wider range of fats of both plant and animal origin (Vermeersch \& Vanschroubroek, 1968; Carew et al. 1964), including by-products of edible oil refining (Menge $\&$ Beal, 1973), have been used to improve the performance of broiler chicks. The value of fat as an economic ingredient in the diet of the turkey has been clearly demonstrated (Touchburn \& Naber, 1966).

In the total animal production system, however, the beneficial effects of a higher 
nutrient density on the cumulative production costs need to be balanced against the cost of producing feed of a higher energy density. Overall efficiency, i.e. the margin over feed costs, is also influenced by a third factor, viz the value per unit of meat produced. The use of fats to raise the dietary energy density has specific effects on both input and output relationships through (a) their direct, non-linear effect on diet cost, and (b) their influence on the quality of the end-product. Although the relationship between fatty acid composition of dietary fat and energy value can be quantified, the relationship between the former and carcass characteristics is more complex.

Carcass effects. The criteria of carcass quality differ between pigs, broilers and turkeys, but the level of carcass fat is a significant factor in each case. As an energy source, dietary fat influences carcass composition through its relationship with the energy density of the diet and more significantly through changes in the ratio of protein:energy. In the broiler, dietary energy level alone has only a small effect on body composition when compared with the effects of different energy:protein values (Farrell, 1974). Although backfat is the major anatomical site of fatty acid deposition in the pig, and the one most readily measured, considerable quantities of fat are present as inter- and intra-muscular fat and perirenal fat. In the growing pig, the effects of dietary energy on carcass composition are conflicting. Lucas et al. (1960) found significant correlations between dietary energy density and backfat thickness. Richmond \& Berg (197I) on the other hand, observed that the amount and distribution of dissectable carcass fat were determined by the live weight of the animal and not by energy intake. The sex and breed of the pig had no effect on the distribution of fat (Richmond \& Berg, 1971). These effects have been adequately collated by the Agricultural Research Council (I98I) and further discussion lies outside the scope of this paper. In the broiler, excessive carcass fat levels are a problem of concern to the industry; the control of this problem will probably come through a more precise accounting of excess dietary energy and, significantly, the genetic influence (Leclercq et al. 1980) rather than reducing the fat content of the diet.

The regulation of lipogenesis by dietary fats is recognized in both mammals and birds, but the contribution of lipogenesis to total body fat mass has been estimated infrequently. In the chicken, as in the turkey, the liver is the main site of lipogenesis (Leveille et al. 1975; Borron \& Britton, 1977), in contrast to the predominant role of adipose tissue in fatty acid synthesis in the pig (O'Hea \& Leveille, 1969). Lipogenesis in the pig, the chick and the turkey is suppressed by an increase in the intake of dietary fat as well as of protein. Fatty acid synthetase activity is considered to be of major importance in the long-term response in lipogenesis to dietary fat in the chicken (Liou \& Donaldson, 1973) and turkey (Rosebrough et al. I98I), whereas Allee et al. (1971) indicated that malic enzyme was more closely related to lipogenic activity in the pig. The nature of the dietary fat, and in particular its linoleic acid content, may have an important influence on the control of fatty acid synthesis and desaturation in the bird (Balnave \& Pearce, 1969; Infield \& Annison, 1973) but not in the pig (Allee et al. 1971). 
Dietary fat has a pronounced effect on the composition of the carcass fat of pigs (McDonald \& Hamilton, 1976) and poultry (Salmon \& O'Neil, 1973). Factors which affect the fatty acid composition of carcass fat, although of lesser importance than dietary fat, include ambient temperature during growth, plane of nutrition, the anatomical location of the fat and the level of dietary copper. In turn, the fatty acid composition of carcass fat has a significant bearing on quality through its direct relationship with the softness or hardness of carcass fat in the pig and its effect on more subjective measurements of quality in the broiler or turkey such as finish, flavour, texture and cooking loss. Because of the varying contribution to fat accretion of lipogenesis from carbohydrates and amino acids, and the contributory effects of the nutritional status of the animal and its environmental temperature, simple relationships between dietary fat and carcass fatty acid composition cannot be drawn (Fig. 1). Two approaches may be used to the solution of this difficulty: empirical correlations of observations made under a wide range of nutritional, environmental and genetic conditions or a more fundamental approach through the use of modelling. Dynamic models of broiler and pig growth already exist which adequately describe the effects of fats as energy sources on the accretion of body protein and fat. Extension and modification of these models to incorporate the fluxes of individual or common groups of fatty acids through oxidative or transfer pathways, and their turnover rates in adipose tissue, may prove a feasible means of predicting the effect of dietary fats on the level and composition of carcass fat.

Essential fatty acids. The essential fatty acid (EFA) requirement of the growing pig up to $30 \mathrm{~kg}$ live weight is estimated to be $3 \%$ of dietary energy, expressed as linoleic acid, declining to $\mathrm{I} \cdot 5 \%$ at heavier weights (Agricultural Research Council, 1981). The minimum recommendation for the chick probably does not exceed ro $\mathrm{g} / \mathrm{kg}$ of diet (Agricultural Research Council, 1975), or approximately $3.3 \%$ of dietary energy. It is generally assumed that a large proportion of the requirement is met from the linoleate content of dietary cereals. However, changes in the nature of

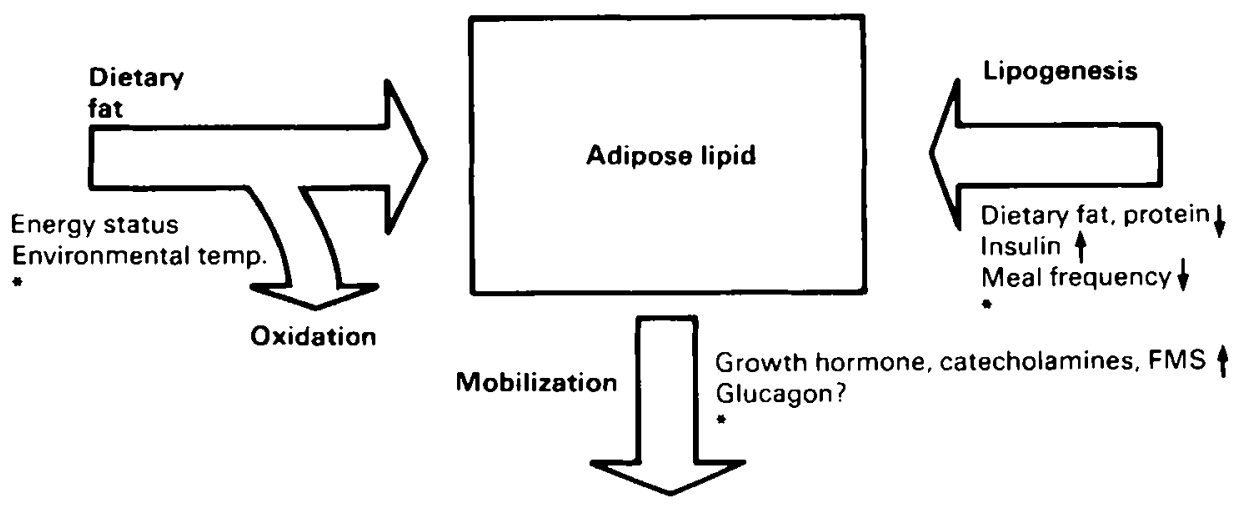

Fig. 1. Dynamics of adipose lipid accretion and inter-relationships which influence adipose lipid composition. "Process where a fatty acid specificity occurs. 
dietary formulations for pigs and poultry, with less reliance on a cereal base and the introduction of less well-defined and more variable raw materials, has meant that a greater proportion of the requirement has had to be met from a supplemental fat source. More importantly, some studies have suggested that the need for linoleate by the broiler chick is considerably higher than recommended values, especially for the rapidly growing male (Menge, 1970; Carew \& Foss, 1973). Where growth is used as the criterion of EFA adequacy, it has to be questioned whether the response observed is due to the supply of EFA or to additional dietary energy through underestimation of the ME value of the source of essential fatty acids.

Less attention has been paid to the endogenous factors regulating EFA metabolism, of which the activity of fatty acid desaturase enzymes may be important. Oleic acid, endogenously produced by desaturation of stearic acid, is known to compete with linoleic acid for the same desaturase enzyme. Thus indirectly the requirement for linoleate may be increased by stimulation of the stearic acid desaturase, e.g. by high levels of circulating insulin. The dietary proportions of carbohydrate and fat may thus have a significant influence on the EFA requirement of the growing animal.

\section{Some specific applications}

The laying hen. The significant regressions observed between energy and nutrient density and the response of the laying hen in terms of $\mathrm{ME}$ intake, bodyweight gain and egg weight have been used to construct models of layer production which accommodate both variations in input costs of raw materials and in the value of the output of hens and eggs (De Groote, 1972). In this way, the economically optimal feed composition for a variety of economic situations can be predicted. Depending primarily on the relative costs of fats and cereals, the former can provide economic solutions through their effect on both feed price per unit mass and per unit of dietary energy. Where supplemental fat has been used to increase the energy concentration of layers' diets, the qualitative effects are consistent with a response to dietary energy. In quantitative terms however, the apparent $M E$ contributed by the fat has been found to be greater than its nominal or calculated ME (Sell et al. 1979), an effect which has been partly attributed to the effects of dietary fat on the rate of passage of the carbohydrate fraction of the diet (Mateos \& Sell, 198I). The energetic efficiency of fat in the laying hen appears to be high (ME to net energy conversion of approximately $96 \%$ ), and to remain constant irrespective of the environmental temperature to which the birds are exposed (Valencia et al. 1980). In contrast to the broiler, feeding supplemental fat to the laying hen during periods of heat stress appears to be beneficial at environmental temperatures up to $30^{\circ}$ (Reid, 198I). Beyond this temperature, feed and $M E$ intake decline at a rate faster than that of the maintenance energy requirements of the bird. Although under these conditions the inclusion of supplemental fat in the diet is capable of supplying additional energy through an increase in dietary energy concentration, the effect is relatively small and 
insufficient to meet demands. The energy demand of the higher respiratory activity of the bird associated with its attempt to dissipate body heat, places a further drain on the energy supply.

Of greater significance than its role as an energy source in the laying hen, is the application of supplementary fat to meet the essential fatty acid needs for egg production. In the laying hen the function which shows the greatest requirement for linoleate is egg weight. Because of the high efficiency with which linoleate is absorbed by both the immature and adult bird and the large depots of linoleate which occur in adipose tissue, large differences in estimates of requirements have been observed, relating to whether the birds had been previously depleted of linoleate. For birds previously maintained over an extended period on diets containing low levels of linoleate, the requirements for maximum egg size were met by dietary linoleate levels of $20-25 \mathrm{~g} / \mathrm{kg}$ (Agricultural Research Council, 1975). For birds reared and maintained on conventional rations, the requirement for maximum egg size appeared to be satisfied with a much lower level of linoleate ( $12-14 \mathrm{~g} / \mathrm{kg}$ diet). Even within these categories, there are contradictory results concerning the effects of graded levels of dietary linoleate (Balnave \& Brown, 1968; Menge, 1968) which may be attributed to different protein:energy values, age, and stage of egg production between the studies. More recently, Whitehead (I98I) has suggested that the linoleate requirement of the laying hen may be little more than the physiological requirement for maintenance and growth and that the egg weight response is attributable to higher levels of circulating lipid which can be supplied by linoleate or oleate. A proportion of the layers' requirements has to be supplied by supplemental fat, usually in the form of a vegetable oil. Again, models of layer production are useful to predict economic optima in relation to the input costs of additional dietary linoleate and the output value having regard to the changing market price structure for eggs of different weights.

There is evidence (Balnave, 1971) that the increased egg weight in birds fed on maize-oil supplements is due to an increase in the size of the ovum, and the increased yolk dry matter of the eggs is due to increased fat deposition in the yolk. Clearly, the intermediary mechanisms are complex since hepatic lipogenesis is depressed by an increase in dietary linoleate (Balnave \& Pearce, 1969) implying either an enhanced direct transfer of dietary lipid to the egg, or an increase in mobilization since the net uptake was increased. Despite the known influence of oestrogen and fat mobilizing hormones on circulating linoleate levels, the hormonal control of these intermediary metabolic processes is incompletely understood and is likely to be a rewarding area for further study.

The pregnant/lactating sow. Fat supplementation of the diet of sows during late pregnancy and early lactation has been shown to increase the fat and energy content of sows' milk and to improve the survival rate of piglets, particularly those of low birth weight (Boyd et al. 1978a; Seerley et al. 198I). Fat supplementation of the dam's diet raised plasma glucose concentration in the piglets for $24 \mathrm{~h}$ after birth (Boyd et al. 1978b). This effect may well account for the improved survival of small piglets, since the rapid depletion of glycogen reserves of the neonate and the 
relatively slow release of fatty acids from adipose tissue in the critical period between birth and first suckling are important factors in the high mortality rate associated with this 'at-risk' group.

It has been shown that the concentration of linoleate in sows' milk can be increased by feeding linoleate-rich diets to lactating sows, or by increasing the linoleate content of the adipose tissue of the sow prior to parturition (SalmonLegagneur, 1963). Consumption of linoleate-enriched sows' milk can result in a significant concentration of linoleate in the adipose tissue of suckling pigs (Miller et al. 1971); however there is little information on the specific influence of polyunsaturated fatty acid-enriched diets on sow fertility, or on the viability of their litters.

\section{REFERENCES}

Agricultural Research Council (1975). The Nutrient Requirements of Farm Livestock, no. I, Poultry. London: Agricultural Research Council.

Agricultural Research Council (1981). The Nutrient Requirements of Pigs. Slough: Commonwealth Agricultural Bureaux.

Allee, G. L., O'Hea, E. K., Leveille, G. A. \& Baker, D. H. (1971). f. Nutr. ror, 869.

Balnave, D. (1971). F. Sci. Fd Agric. 22, 25.

Balnave, D. \& Brown, W. O. (1968). Poult. Sci. 47, 1212.

Balnave, D. \& Pearce, J. (1969). Comp. Biochem. Physiol. 29, 539.

Blaxter, K. L. (1962). The Energy Metabolism of Ruminants. London: Hutchinson.

Borron, D. C. \& Britton, W. M. (1977). Poult. Sci. 56, 353.

Boyd, R. D., Moser, B. D., Peo, E. R. \& Cunningham, P. J. (1978a). F. Anim. Sci. 47, 4.

Boyd, R. D., Moser, B. D., Peo, E. R. \& Cunningham, P. J. (1978b). F. Anim. Sci. 47, 873 .

Carew, L. B. \& Foss, D. C. (1973). Poult. Sci. 52, 1676.

Carew, L. B., Hopkins, D. T. \& Nesheim, M. C. (1964). f. Nutr. 83, 300.

Cooke, R., Lodge, G. A. \& Lewis, D. (1972). Anim. Prod. 14, 219.

Dale, N. M. \& Fuller, H. L. (1980). Poult. Sci. 59, 1434.

De Groote, G. (1969). Rep. Gov. Res. Stn., Merelbeke, Belgium. p. 143.

De Groote, G. (1972). Br. Poult. Sci. 13, 503.

De Groote, G., Reyntens, N. \& Amich-Gali, J. (I971). Poult. Sci. 50, 808.

Farrell, D. J. (1974). Br. Poult. Sci. 15, 25.

Fisher, C. \& Wilson, B. J. (1974). In Energy Requirements of Poultry, p. 151 [T. R. Morris and B. M. Freeman, editors]. Edinburgh: British Poultry Science Ltd.

Freeman, C. P. (1976). In Digestion in the Fowl, p. 177 [K. N. Boorman and B. M. Freeman, editors]. Edinburgh: British Poultry Science Ltd.

Freeman, C. P., Holme, D. W. \& Annison, E. F. (1968). Br. f. Nutr. 22, 651.

Greeley, M. G., Meade, R. J., Hanson, L. E. \& Nordstrom, J. (1964). F. Anim. Sci. 23, 816.

Hillcoat, J. B. \& Annison, E. F. (1974). In 6th Symposium on Energy Metabolism in Farm Animals, p. 177 [K. H. Menke, H. J. Lantzch and J. R. Reichl, editors]. E.A.A.P. Publ. no. I4. Hohenheim, Germany: E.A.A.P.

Infield, J. M. \& Annison, E. F. (1973). Br. F. Nutr. 30, 545 .

Kubena, L. F., Reece, F. N., Deaton, J. W. \& May, J. D. (1973). Poult. Sci. 52, 1691.

Leclercq, B., Blum, J. C. \& Boyer, J. P. (1980). Br. Poult. Sci. 21 , 107.

Leveille, G. A., Romsos, D. R., Yeh, Y. Y. \& O'Hea, E. K. (1975). Poult. Sci. 54, 1075.

Lewis, D. \& Payne, C. G. (1966). Br. Poult. Sci. 6, 209.

Liebbrandt, V. D., Hays, V. W., Ewan, R. C. \& Speer, V. C. (1975). J. Anim. Sci. 40, 1081.

Liou, G. I. \& Donaldson, W. E. (1973). Can. F. Biochem. 51, 1029.

Lucas, I. A. M., McDonald, I. \& Calder, A. F. C. (1960). f. agric. Sci., Camb. 54, 8 I.

McDonald, B. E. \& Hamilton, R. M. G. (1976). Can. Y. Anim. Sci. 56, 671 .

Mateos, G. G. \& Sell, J. L. (1981). Poult. Sci. 60, 1925. 
Menge, H. (1968). $\mathcal{F}$. Nutr. 95, 578 .

Menge, H. (1970). Poult. Sci. 49, 178.

Menge, H. \& Beal, R. E. (1973). Poult. Sci. 52, 219.

Miller, G. M., Conrad, H. \& Harrington, R. B. (1971). f. Anim. Sci. 32, 79.

O'Hea, E. K. \& Leveille, G. A. (1969). F. Nutr. 99, $33^{8}$.

Reid, B. L. (1981). F. Am. Oil Chem. Soc. 58, 306.

Richmond, R. J. \& Berg, R. T. (I971). Can. F. Anim. Sci. 51, 523.

Rosebrough, R. W., Steele, N. C., Frobish, L. T. \& Weinland, B. (1981). Poult. Sci.60, 1931.

Salmon, R. E. \& O'Neil, J. B. (1973). Poult. Sci. 52, 302.

Salmon-Legagneur, E. (1963). C.R. Acad. Sci., Paris 256, 1372.

Seerley, R. W., Snyder, R. A. \& Campbell, H. C. (1981). F. Anim. Sci. 52, 542.

Sell, J. L., Tenesaca, L. G. \& Bales, G. L. (1979). Poult. Sci. 58, 900.

Shannon, D. W. F. (1971). Y. agric. Sci., Camb. 76, 217.

Touchburn, S. P. \& Naber, E. C. (1966). - I3th Wld's Poult. Congr., Kiev, p. r 90.

Valencia, M. E., Maiorino, P. M. \& Reid, B. L. (1980). Poult. Sci. 59, 2071.

Vermeersch, G. \& Vanschoubroek, F. (1968). Br. Poult. Sci. 9, I3.

Whitehead, C. C. (1981). Br. Poult. Sci. 22, 525. 